\title{
Effectiveness of Nutritional Intervention in Reduction of Gastrointestinal Toxicity during External Beam Radiotherapy in Women with Gynecological Tumors
}

\section{Jaime Humberto Soto-Lugo*, Miguel Ángel Souto-Del Bosque and Carlos Alberto Vázquez-Martínez}

Department of Radio-oncology, Centro Médico del Noreste UMAE 25, IMSS, Monterrey, N.L., Mexico

Received for publication: 14 December 2016; accepted for publication: 25 February 2017

Available online: 4 August 2017

\section{KEYWORDS \\ Gynecologic tumor; Low-FODMAP diet; \\ Quality of life; Gastrointestinal toxicity}

\begin{abstract}
Objective: To assess if nutritional intervention with a diet low in fermentable oligosaccharides, disaccharides, monosaccharides and polyols (FODMAP) decreases acute gastrointestinal toxicity induced by pelvic external beam radiotherapy in patients with gynecologic tumors. Material and methods: Single-center, randomized, prospective clinical trial comparing patients on a low-FODMAP diet vs. standard Mexican diet, designed to detect an $80 \%$ decrease in Grade 1-2 acute gastrointestinal toxicity in the standard diet group to $25 \%$ of Grade 1-2 acute gastrointestinal toxicity in the low-FODMAP diet group. Results: Thirteen patients were recruited per group, with higher gastrointestinal toxicity grade $1-2(85 \mathrm{vs} .77 \%)$ and 3 ( 23 vs. $0 \%$ ) being reported in the standard diet group with regard to the low-FODMAP diet $(p=0.16)$. The low-FODMAP diet group had a lower end of treatment symptom score in the cervical cancer patient quality of life questionnaire $(1.41$ vs. $1.85 ; p=0.01)$ and lower ECOG mean deterioration $(0.61[S D \pm 0.5]$ vs. $0.23[S D \pm 0.43] ; p=0.049)$. Excellent adherence to the diet was shown by $85 \%$ of patients. No factors associated with the presence of grade 3 gastrointestinal toxicity were found. Conclusion: Implementation of a low-FODMAP diet during pelvic external beam radiation therapy is a low-cost and high-adherence measure that reduces end-of-treatment performance status and symptom deterioration in patients with cervical cancer. (creativecommons.org/licenses/by-nc-nd/4.0/).
\end{abstract}

${ }^{*} E$-mail for correspondence: jaimeh.sotolugo@gmail.com (J.H. Soto-Lugo) 


\section{INTRODUCTION}

Uterine cervix and uterine body malignant tumors represent in women the fourth and sixth place in incidence, and the fourth and fourteenth place in cancer-related mortality worldwide. In Mexico, cervical cancer is the second most common cancer in women in terms of incidence and mortality, and uterine body cancer occupies the ninth and thirteenth place with regard to these parameters. In addition, these figures are expected to increase by $2020^{1,2}$.

Treatment with external beam radiation therapy (EBRT) or teletherapy is used in $60-71 \%$ of women with cervical cancer and in $38-45 \%$ of those with uterine body tumors sometime during the course of the disease ${ }^{3-5}$. The main adverse effect of this therapy is gastrointestinal (GI) toxicity, which occurs at mild-to-moderate grades in $70-90 \%$ of patients and severe grades (3-4) in around $3 \%{ }^{6}$, with incidence and severity increasing with commonly present factors such as concomitant use of chemotherapy, which doubles the risk for grade $\geq 3 \mathrm{Gl}$ toxicity ${ }^{7}$.

Women who experience acute GI toxicity during pelvic EBRT suffer a negative impact on abdominal symptoms, which also affects their nutritional status and quality of life. In addition, treatment prolongation or discontinuation due to these symptoms increases the risk for suboptimal results in disease control, life expectancy, and quality of life . $^{8}$

Multiple interventions related to modification of treatment technical aspects have been developed to decrease EBRT-associated GI toxicity over the past few decades; however, it remains the main adverse effect in these patients, and these measures cannot be employed in all centers owing to the technical and economic requirements they involve ${ }^{9-16}$.

With regard to different dietary interventions that have been assessed, their effectiveness has not been conclusively corroborated in spite of being a readily accessible and easy to implement option, which makes their use feasible in all healthcare centers, either alone or in combination with other measures for the reduction of this toxicity ${ }^{17-20}$.

Based on the lack of conclusive evidence on GI toxicity reduction with nutritional interventions using the modification of a single dietary element in radiotherapy treated patients, the advantage of the low fructose, fermentable oligosaccharides, disaccharides, monosaccharides and polyols (FODMAP) diet lies in its intervention on multiple factors that influence radiation-induced enteropathy such as vowel motility regulation, lactose and osmotic agents restriction, and bacterial flora modification ${ }^{9,21,22}$, together with an improvement observed in abdominal symptoms of patients with inflammatory bowel disease, which has similarities with radiation-induced damage in its pathogenesis, and reported high compliance ${ }^{23-27}$.

This is why assessment of this type of nutritional intervention is necessary in EBRT-treated patients in order to improve treatment tolerance and in this way positively influence patients' oncologic outcomes and quality of life.

The main purpose of this trial was to assess if nutritional intervention by means of a FODMAP diet decreases pelvic EBRT-induced acute GI toxicity in patients with gynecologic tumors when compared with a standard Mexican diet.

\section{MATERIAL AND METHODS}

\section{Patient selection and eligibility criteria}

Patients diagnosed with cervical cancer or endometrial cancer at the Northeastern National Medical Center UMAE 25 of the Mexican Institute of Social Security in Monterrey, Nuevo León, were included. To be considered eligible, patients had to be between 18 and 70 years old at the moment of enter ing the study, have histopathological corroboration of diagnosis, performance status according to the Eastern Cooper ative Oncology Group (ECOG) of 0-2, have adequate kidney, liver and bone marrow function, not being pregnant or in the postpartum period, and be candidates for radical or ad juvant treatment with EBRT with or without concomitant chemotherapy. Patients who had received prior treatment with pelvic radiotherapy, or with inflammatory bowel dis ease, active severe comorbidity, or active collagen disease, or those with distant metastasis according to disease-exten=sion studies with chest X-ray and abdominopelvic CT scan were excluded.

The study protocol was approved by the Research and Ethics in Health Research Local Committee and informed consent was obtained from the patient for her participation in the study according to institutional guidelines.

\section{Surgery}

The patients treated with surgery of the primary tumor who were candidates for adjuvant therapy were treated with hysterectomy plus bilateral salpingo-oophorectomy with or without lymphadenectomy.

\section{Chemotherapy}

In patients who were candidates for concomitant chemotherapy, cisplatin was used at a dose of $40 \mathrm{mg} / \mathrm{m}^{2}$ on radiotherapy days $1,8,15,22$, and 29 and in case of contrain dication for this drug, carboplatin was used at dose of an area under the curve (AUC) of 1.5 according to Calvert's formula.

\section{Radiotherapy}

All patients received EBRT with tridimensional conformat technique, at a dose of $50 \mathrm{~Gy}$ in $2 \mathrm{~Gy}$ fractions or $50.4 \mathrm{~Gy}$ in $1.8 \mathrm{~Gy}$ fractions.

\section{Diet}

The types of diet to be assigned comprised a diet low in fructose, oligosaccharides, disaccharides, monosaccharides, olyols and polyols (FODMAP) specified by means of an alimentary guideline. The assessment of adherence to this diet was made by means of weekly self-assessment with a Likert-type scale with adherence values $\geq 75 \%$ of the time, $50-75 \%$ of the time, $25-50 \%$ of the time, and $<25 \%$ of the time. The other diet was a standard Mexican diet according to recommendations of the Mexican Official Standard NOM043-SSA2-2012, Basic health services. Promotion and education for alimentary health. Criteria to offer guidance. 


\section{Safety}

At the beginning of EBRT, symptoms, weight, performance status (PS) and quality of life (QoL) were assessed by applying the European Organization for Research and Treatment of Cancer (EORTC) QLQ C-3028,29 questionnaire to all patients, as well as the specific modules for cervical $(\mathrm{CX}-24)^{30}$ or endometrial cancer $(\mathrm{EN}-24)^{31}$, according to the primary tumor. Subsequently, the degree of $\mathrm{GI}$ toxicity was assessed weekly according to the National Cancer Institute ( $\mathrm{NCl}$ ) v4.03 scale, and medical and/ or hospital management was provided when it was required.
At the end of the EBRT treatment, patients' QoL, weight, and GI toxicity were newly assessed.

\section{Study design}

A single-center, prospective, randomized clinical trial was carried out, with patients being assigned to the FODMAP diet or standard Mexican Official Standard (NOM - Norma Oficial Mexicana) diet groups by means of randomization tables.

The study was designed to detect a decrease from $80 \%$ of grade 1-2 acute GI toxicity in the standard diet group to

Table 1 Patient characteristics by assigned diet

\begin{tabular}{|c|c|c|c|c|}
\hline & & FODMAP n (\%) & NOM n (\%) & $\mathrm{p}$ \\
\hline Mean age & & 46 & 43 & 0.8 \\
\hline \multirow[t]{9}{*}{ Primary tumor } & & & & 1 \\
\hline & Cervix & $10(77)$ & $10(77)$ & \\
\hline & 1 & $1(7)$ & $1(7)$ & \\
\hline & II & $5(38)$ & $5(38)$ & \\
\hline & III & $4(31)$ & $4(31)$ & \\
\hline & Endometrium & $3(23)$ & $3(23)$ & 0.54 \\
\hline & I & $0(0)$ & $1(7)$ & \\
\hline & II & $0(0)$ & $0(0)$ & \\
\hline & III & $3(23)$ & $2(15)$ & \\
\hline \multirow[t]{4}{*}{ ECOG } & & & & 0.8 \\
\hline & 0 & $2(15)$ & $3(23)$ & \\
\hline & 1 & $8(62)$ & $8(62)$ & \\
\hline & 2 & $3(23)$ & $2(15)$ & \\
\hline \multirow[t]{3}{*}{ Comorbidities } & & & & 0.39 \\
\hline & Yes & $3(23)$ & $5(38)$ & \\
\hline & No & $10(77)$ & $8(62)$ & \\
\hline \multirow{3}{*}{$\begin{array}{l}\text { Primary tumor previous } \\
\text { surgery }\end{array}$} & & & & 0.68 \\
\hline & Yes & $4(31)$ & $5(38)$ & \\
\hline & No & $9(69)$ & $8(62)$ & \\
\hline \multirow[t]{3}{*}{ Concomitant chemotherapy } & & & & 0.65 \\
\hline & Yes & $9(69)$ & $10(77)$ & \\
\hline & No & $4(31)$ & $3(23)$ & \\
\hline \multirow[t]{3}{*}{ Radiotherapy dose } & & & & 0.68 \\
\hline & $50.4 \mathrm{~Gy} / 28 \mathrm{fr}$. & $8(62)$ & $9(69)$ & \\
\hline & 50 Gy/25 fr. & $5(38)$ & $4(31)$ & \\
\hline \multirow{2}{*}{$\begin{array}{l}\text { Volume of bowel portion } \\
\text { receiving } 45 \mathrm{~Gy}>195 \mathrm{cc}\end{array}$} & & & & 0.3 \\
\hline & Yes & $13(100)$ & $12(93)$ & \\
\hline \multirow{3}{*}{$\begin{array}{l}\text { Volume of colon receiving } \\
\qquad 40 \mathrm{~Gy}>60 \%\end{array}$} & & & & 0.14 \\
\hline & Yes & $13(100)$ & $11(85)$ & \\
\hline & No & $0(0)$ & $2(15)$ & \\
\hline \multirow[t]{4}{*}{ Follow-up } & & & & 1 \\
\hline & 5 weeks & $4(31)$ & $4(31)$ & \\
\hline & 6 weeks & $5(38)$ & $5(38)$ & \\
\hline & $>6$ weeks & $4(31)$ & $4(31)$ & \\
\hline
\end{tabular}


$25 \%$ of grade 1-2 acute GI toxicity in FODMAP-diet patients, with an alpha-value of 0.005 and statistical power of $80 \%$. Thirteen patients were planned to be recruited per group, for a total of 26 patients.

\section{RESULTS}

Twenty-six patients who agreed to participate in the study were recruited from August to October 2016 at the North- eastern National Medical Center. The characteristics of the patients assigned to each type of diet are presented in table 1.

\section{Toxicity}

The results on the highest degree of GI toxicity experienced by the patients according to the assigned diet type are presented in table 2 .

Table 3 shows the incidence according to the type and grade of toxicity experienced by the patients according to

Table 3. Type and grade of gastrointestinal toxicity according to assigned diet

\begin{tabular}{|c|c|c|c|c|}
\hline Toxicity & Grade & FODMAP n (\%) & NOM n (\%) & $\mathrm{p}$ \\
\hline \multirow[t]{5}{*}{ Bloating } & 0 & $13(100)$ & $11(86)$ & 0.7 \\
\hline & 1 & $0(0)$ & $0(0)$ & \\
\hline & 2 & $0(0)$ & $1(7)$ & \\
\hline & 3 & $0(0)$ & $1(7)$ & \\
\hline & 4 & $0(0)$ & $0(0)$ & \\
\hline \multirow[t]{5}{*}{ Pain } & 0 & 7 (54) & $8(62)$ & 0.6 \\
\hline & 1 & $4(31)$ & $2(15)$ & \\
\hline & 2 & $2(15)$ & $2(15)$ & \\
\hline & 3 & $0(0)$ & $1(7)$ & \\
\hline & 4 & $0(0)$ & $0(0)$ & \\
\hline \multirow[t]{5}{*}{ Nausea } & 0 & $3(23)$ & $2(15)$ & 0.83 \\
\hline & 1 & $8(62)$ & 7 (54) & \\
\hline & 2 & $2(15)$ & $3(23)$ & \\
\hline & 3 & $0(0)$ & $1(7)$ & \\
\hline & 4 & $0(0)$ & $0(0)$ & \\
\hline \multirow[t]{5}{*}{ Vomiting } & 0 & $6(46)$ & 7 (54) & 0.78 \\
\hline & 1 & $4(31)$ & $2(15)$ & \\
\hline & 2 & $3(23)$ & $3(23)$ & \\
\hline & 3 & $0(0)$ & $1(7)$ & \\
\hline & 4 & $0(0)$ & $0(0)$ & \\
\hline \multirow[t]{5}{*}{ Proctitis } & 0 & $10(77)$ & $10(77)$ & 1 \\
\hline & 1 & $3(23)$ & $3(23)$ & \\
\hline & 2 & $0(0)$ & $0(0)$ & \\
\hline & 3 & $0(0)$ & $0(0)$ & \\
\hline & 4 & $0(0)$ & $0(0)$ & \\
\hline \multirow[t]{5}{*}{ Rectal pain } & 0 & $10(77)$ & $10(77)$ & 0.87 \\
\hline & 1 & $3(23)$ & 2 (15) & \\
\hline & 2 & $0(0)$ & $1(7)$ & \\
\hline & 3 & $0(0)$ & $0(0)$ & \\
\hline & 4 & $0(0)$ & $0(0)$ & \\
\hline \multirow[t]{5}{*}{ Diarrhea } & 0 & $5(38)$ & $4(31)$ & 0.43 \\
\hline & 1 & $2(15)$ & $4(31)$ & \\
\hline & 2 & $6(46)$ & $3(23)$ & \\
\hline & 3 & $0(0)$ & $2(15)$ & \\
\hline & 4 & $0(0)$ & $0(0)$ & \\
\hline \multirow[t]{5}{*}{ Constipation } & 0 & $12(93)$ & $12(93)$ & 1 \\
\hline & 1 & 1 (7) & 1 (7) & \\
\hline & 2 & $0(0)$ & $0(0)$ & \\
\hline & 3 & $0(0)$ & $0(0)$ & \\
\hline & 4 & $0(0)$ & $0(0)$ & \\
\hline
\end{tabular}


Table 2 Incidence of gastrointestinal toxicity according to assigned diet; $p=0.16$

\begin{tabular}{lcc}
\hline Toxicity & FODMAP $\mathrm{n}(\%)$ & NOM $\mathrm{n}(\%)$ \\
\hline 0 & $2(15)$ & $0(0)$ \\
1,2 & $11(85)$ & $10(77)$ \\
3 & $0(0)$ & $3(23)$ \\
4 & $0(0)$ & $0(0)$ \\
\hline
\end{tabular}

Table 4. Adherence to the FODMAP diet

\begin{tabular}{lc}
\hline Compliance & $\mathrm{n}(\%)$ \\
\hline Excellent & $11(85)$ \\
Regular & $2(15)$ \\
Non-compliance & $0(0)$ \\
\hline
\end{tabular}

Table 5. Weight loss and ECOG at the end of external beam radiotherapy

\begin{tabular}{|c|c|c|c|c|c|c|c|c|c|}
\hline & & \multicolumn{3}{|c|}{ FODMAP } & \multicolumn{3}{|c|}{ NOM } & \multicolumn{2}{|c|}{$\mathrm{p}$} \\
\hline \multirow{3}{*}{\multicolumn{2}{|c|}{$\begin{array}{l}\text { Weight loss } \\
\text { Final ECOG } \\
\text { ECOG decrease }\end{array}$}} & \multicolumn{3}{|c|}{$2.43 \mathrm{~kg}(\mathrm{SD} \pm 2.33)$} & \multicolumn{3}{|c|}{$3.12 \mathrm{~kg}(\mathrm{SD} \pm 3.17)$} & \multicolumn{2}{|c|}{0.48} \\
\hline & & \multicolumn{3}{|c|}{$1.3(S D \pm 0.63)$} & \multicolumn{3}{|c|}{$1.3(S D \pm 0.63)$} & \multicolumn{2}{|c|}{1} \\
\hline & & \multicolumn{3}{|c|}{$0.23(S D \pm 0.43)$} & \multicolumn{3}{|c|}{$0.61(S D \pm 0.5)$} & \multicolumn{2}{|c|}{0.049} \\
\hline \multirow{2}{*}{ te 0.} & & \multicolumn{3}{|c|}{ Initial } & \multicolumn{3}{|c|}{ Final } & \multicolumn{2}{|c|}{ Change } \\
\hline & & FODMAP & NOM & $\mathrm{p}$ & FODMAP & NOM & $\mathrm{p}$ & FODMAP & NOM \\
\hline \multirow[t]{14}{*}{ QLQ C-30 } & $\begin{array}{l}\text { Global quality } \\
\text { of life }\end{array}$ & 4.90 & 4.90 & 0.95 & 5.03 & 4.92 & 0.84 & 0.13 & 0.02 \\
\hline & Physical & 1.58 & 1.64 & 0.76 & 1.58 & 1.76 & 0.17 & 0 & 0.12 \\
\hline & Role & 2.00 & 1.69 & 0.35 & 1.88 & 1.69 & 0.51 & -0.12 & 0 \\
\hline & Emotional & 1.86 & 2.09 & 0.47 & 1.57 & 1.53 & 0.86 & -0.29 & -0.56 \\
\hline & Social & 1.92 & 1.57 & 0.34 & 1.80 & 2.00 & 0.58 & -0.12 & 0.43 \\
\hline & Fatigue & 2.15 & 1.99 & 0.60 & 2.40 & 2.09 & 0.22 & 0.25 & 0.10 \\
\hline & Nausea/vomiting & 1.80 & 1.69 & 0.80 & 2.00 & 1.76 & 0.43 & 0.20 & 0.07 \\
\hline & Pain & 1.96 & 1.96 & 1.00 & 1.92 & 1.61 & 0.31 & -0.04 & -0.35 \\
\hline & Dyspnea & 1.46 & 1.46 & 1.00 & 1.38 & 1.54 & 0.45 & -0.08 & 0.08 \\
\hline & Insomnia & 1.92 & 1.85 & 0.94 & 1.85 & 1.69 & 0.64 & -0.07 & -0.16 \\
\hline & Appetite loss & 2.15 & 1.46 & 0.69 & 2.15 & 2.23 & 0.83 & 0 & 0.77 \\
\hline & Constipation & 2.00 & 2.15 & 0.72 & 1.46 & 1.54 & 0.74 & -0.54 & -0.61 \\
\hline & Diarrhea & 1.08 & 1.15 & 0.55 & 2.15 & 2.31 & 0.59 & 1.07 & 1.16 \\
\hline & $\begin{array}{l}\text { Financial } \\
\text { difficulties }\end{array}$ & 2.46 & 1.92 & 0.18 & 2.54 & 1.92 & 0.09 & 0.08 & 0 \\
\hline \multirow[t]{7}{*}{$C X-24$} & Body image & 1.39 & 1.63 & 0.46 & 1.73 & 1.76 & 0.94 & 0.34 & 0.13 \\
\hline & Sexual activity & 1.20 & 1.5 & 0.38 & 1.10 & 1.00 & 0.33 & -0.10 & -0.50 \\
\hline & Symptoms & 1.89 & 1.67 & 0.49 & 1.41 & 1.85 & 0.01 & -0.48 & 0.18 \\
\hline & Lymphedema & 1.10 & 1.10 & 1.00 & 1.00 & 1.00 & 1.00 & -0.10 & -0.10 \\
\hline & Neuropathy & 1.60 & 1.50 & 0.79 & 1.50 & 1.40 & 0.77 & -0.10 & -0.10 \\
\hline & Menopause & 1.90 & 1.60 & 0.40 & 1.70 & 1.30 & 0.14 & -0.20 & -0.30 \\
\hline & Sexual concerns & 1.50 & 1.90 & 0.34 & 2.40 & 2.30 & 0.88 & 0.90 & 0.40 \\
\hline \multirow[t]{11}{*}{ EN-24 } & Sexual interest & 2.33 & 1.33 & 0.10 & 1.33 & 1.00 & 0.37 & -1.00 & -0.33 \\
\hline & Sexual activity & 2.00 & 1.33 & 0.37 & 1.00 & 1.00 & 1.00 & -1.00 & -0.33 \\
\hline & Lymphedema & 1.33 & 1.67 & 0.55 & 1.33 & 1.33 & 1.00 & 0 & -0.34 \\
\hline & Urologic symptoms & 1.41 & 1.66 & 0.60 & 1.50 & 2.25 & 0.25 & 0.09 & 0.59 \\
\hline & $\begin{array}{l}\text { Gastrointestinal } \\
\text { symptoms }\end{array}$ & 1.13 & 1.13 & 1.00 & 1.20 & 1.46 & 0.20 & 0.07 & 0.33 \\
\hline & Body image & 1.33 & 1.67 & 0.67 & 1.00 & 1.33 & 0.37 & -0.33 & -0.34 \\
\hline & Back/pelvis pain & 1.00 & 1.33 & 0.37 & 1.33 & 1.00 & 0.37 & 0.33 & -0.33 \\
\hline & Numbness & 1.33 & 1.67 & 0.51 & 1.33 & 1.33 & 1.00 & 0 & -0.34 \\
\hline & Muscle pain & 1.00 & 1.33 & 0.67 & 1.33 & 1.00 & 0.67 & 0.33 & -0.33 \\
\hline & Hair loss & 2.00 & 3.00 & 0.51 & 1.00 & 2.00 & 0.37 & -1.00 & -1.00 \\
\hline & Taste changes & 2.00 & 2.00 & 1.00 & 1.00 & 1.33 & 0.37 & -1.00 & -0.67 \\
\hline
\end{tabular}


Table 7. Grade 3 gastrointestinal toxicity predictive factors univariate analysis

\begin{tabular}{|c|c|c|}
\hline & Odds ratio $(95 \%$ IC) & $\mathrm{p}$ \\
\hline Cervical cancer & $2.18(0.17-27.00)$ & 0.54 \\
\hline Endometrial cancer & $0.45(0.03-5.78)$ & 0.54 \\
\hline Stage 1 & $0.83(0.03-19.97)$ & 0.91 \\
\hline Stage 2 & $0.77(0.06-9.88)$ & 0.84 \\
\hline Stage 3 & $2.8(0.222-35.28)$ & 0.42 \\
\hline FODMAP diet & $0.11(0.0052-2.39)$ & 0.16 \\
\hline NOM diet & $9(0.41-194)$ & 0.16 \\
\hline ECOG 0 & $0.48(0.02-10)$ & 0.64 \\
\hline ECOG 1 & $0.26(0.02-3.4)$ & 0.30 \\
\hline ECOG 2 & $13.33(0.9-196)$ & 0.05 \\
\hline Comorbidities & $1.41(0.1-18.5)$ & 0.79 \\
\hline Chemotherapy & $0.7(0.05-9.20)$ & 0.79 \\
\hline Bowel volume receiving $45 \mathrm{~Gy}>195 \mathrm{cc}$ & $0.46(0.01-13)$ & 0.65 \\
\hline Rectum volume receiving $40 \mathrm{~Gy}>60 \%$ & $0.09(0.004-2.07)$ & 0.13 \\
\hline Primary tumor surgery & $0.93(0.07-11)$ & 0.96 \\
\hline RT dose $50.4 \mathrm{~Gy}$ & $4.51(0.21-99.20)$ & 0.33 \\
\hline RT dose 50 Gy & $0.21(0.10-4.70)$ & 0.33 \\
\hline
\end{tabular}

the assigned diet. In both groups, the most common GI toxicity was nausea, followed by vomiting ( 54 vs. $46 \%$ ) and diarrhea (62 vs. $69 \%$ ); no grade $3 \mathrm{Gl}$ toxicity events occurred in the low-FODMAP diet group.

\section{Adherence to the FODMAP diet}

Excellent adherence to the diet was considered when a Likert-type diet follow-up score $>75 \%$ was obtained in $50 \%$ or more of assessed weeks; if this score was $50-75 \%$, adherence was regarded as being regular, and below $50 \%$, non-adherence was considered. Data on low-FODMAP diet adherence are reported in table 4.

The excellent adherence to this diet had no significant association with the prevention of $\mathrm{Gl}$ toxicity development of any grade, with an odds-ratio (OR) of 0.93 (95\% Cl: $0.93-$ 11.77; $p=0.96$ ).

\section{Weight loss and performance status}

Table 5 reports weight loss during treatment and endof-treatment ECOG performance status reduction, with greater performance status deterioration being reported in NOM-diet assigned patients with regard to the low-FODMAP diet.

\section{Quality of life}

Initial and final mean scores obtained in the general QoL EORTC QLQ C-30 and endometrial cancer-specific EN-24 tests showed no significant differences; however, in the cervical cancer-specific test, a significant difference was observed, with lower presence of symptoms in the low-FODMAP diet-assigned patients' final questionnaire. The results are presented in table 6.

\section{Factors that influence gastrointestinal toxicity}

No factors having a significant influence on the occurrence of grade $3 \mathrm{Gl}$ toxicity were observed in the univariate anal ${ }^{--}$ ysis (Table 7).

\section{DISCUSSION}

The incidence of GI toxicity in pelvic EBRT-treated patients has been previously reported, with values ranging from 70 to $90 \%$ for grades 1 and 2 and from 3 to $9 \%$ for grades 3 and 4 , whereas in our study we observed a similar incidence of grade 1 and 2 toxicity, with 77 and $85 \%$ according to the low-FODMAP or NOM diet group assigned, respectively. On the other hand, the incidence of grade $3 \mathrm{Gl}$ toxicity was higher than that reported in the literature, with all the events of this grade occurring in the NOM-diet group, which corresponds to $11 \%$ of total patients and $23 \%$ of patients assigned to this diet group. In addition, the type of toxicities experienced by the patients is consistent with that observed in other studies, with main toxicities being nausea, vomit-y ing, and diarrhea, all of them higher in the NOM-diet group.

The higher incidence of GI toxicity in the NOM-diet group was accompanied by greater mean weight loss in these patients $(2.43$ vs. $3.12 \mathrm{~kg})$ and greater mean deterioration of ECOG performance status at treatment completion $(0.61$ $[S D \pm 0.5]$ vs. $0.23[S D \pm 0.43])$, with the difference being statistically significant $(p=0.049)$. In addition, cervical cancer patients who were assigned to this group had more symptoms at treatment conclusion according to the specific QoL CX-24 questionnaire (1.41 vs. $1.85 ; p=0.01$ ).

Hence, in spite of not having achieved a significant decrease in GI toxicity with the low-FODMAP diet, its severity was lower in this group of patients, and this was accompanied by better outcomes in some aspects of QoL in cervical 
cancer patients, as well as less weight loss in the course of treatment.

On the other hand, the excellent low-FODMAP diet-adherence rate (85\%) places it as a tool that can be applied alone or in combination with other measures used to decrease $\mathrm{Gl}$ toxicity that, in addition, by not requiring specific resources or infrastructure, can be implemented at any center.

\section{CONCLUSION}

In conclusion, implementation of a low-FODMAP diet during treatment with pelvic EBRT is a low-cost and high-adherence measure that decreases performance status deterioration and symptoms at treatment conclusion in patients with cervical cancer. Long-term patient follow-up is necessary in order to assess its impact on chronic toxicity, as well as a study with a larger number of patients designed for the reduction of severe toxicity (grade 3-4) during EBRT in order to establish its role in this scenario.

\section{DECLARATION OF INTEREST}

The authors declare not having any conflicts of interests.

\section{REFERENCES}

1. Ferlay J, Soerjomataram I, Ervik M, et al. Globocan 2012 v1.0, Cancer Incidence and Mortality Worldwide. Lyon, France: International Agency for Research on Cancer, 2013. IARC CancerBase No. 11. [Accessed April 4, 2016].

2. Perfil epidemiologico de los tumores malignos en Mexico, SSA, 2011.

3. Barton M. Review of optimal radiotherapy utilization rates, Ingham Institute for Applied Medical Research, Australia, 2013;6:61-88, 26:464-513.

4. Delaney G, Estimation of an optimal radiotherapy utilization rate for gynecologic carcinoma: part I--malignancies of the cervix, ovary, vagina and vulva. Cancer. 2004;101(4):671.

5. Delaney G, Jacob S, Barton M. Estimation of an optimal radiotherapy utilization rate for gynecologic carcinoma: part II--carcinoma of the endometrium. Cancer. 2004;101:682.

6. Nout RA, Smit VT, Putter H, et al. Vaginal brachytherapy versus pelvic external beam radiotherapy for patients with endometrial cancer of high-intermediate risk (PORTEC-2): an open-label, non-inferiority, randomised trial. Lancet. 2010;375:816-23.

7. Andreyev HJN, et al. Does acute gastrointestinal toxicity during radical pelvic radiotherapy predict late gastrointestinal toxicity? A study using the IBDQ and a Vaizey score, more sensitive measures of radiotherapy-induced toxicity than the RTOG or LENT SOM scales, Abstracts for the NCRI Cancer Conferences. 2008. [Accessed April 12, 2016].

8. Andreyev HJ. Gastrointestinal problems after pelvic radiotherapy: the past, the present and the future. Clin Oncol ( $R$ Coll Radiol). 2007;19:790-9.

9. Sher ME, Bauer J. Radiation-induced enteropathy. Am J Gastroenterol. 1990;85:121-8.

10. Letschert JG, Lebesque JV, Aleman BM, et al. The volume effect in radiation-related late small bowel complications: results of a clinical study of the EORTC Radiotherapy Cooperative Group in patients treated for rectal carcinoma. Radiother Oncol. 1994;32:116.

11. Louidice TA, Baxter D, Balint J. Effects of abdominal surgery on the development of radiation enteropathy. Gastroenterol. 1977;73:1093-7.
12. Gay HA, Barthold HJ, O'Meara E, et al. Pelvic normal tissue contouring guidelines for radiation therapy: A Radiation Therapy Oncology Group Consensus Panel Atlas. Int J Radiation Oncol Biol Phys. 2012;83:e353-62.

13. Hymel R, Jones GC, Simone CB, et al. Whole pelvic intensity-modulated radiotherapy for gynecological malignancies: A review of the literature. Crit Rev Oncol Hematol. 2015;94:371-9.

14. Wiesendanger-Wittmer EM, Sijtsema NM, Muijs CT, Beukema JC. Systematic review of the role of a belly board device in radiotherapy delivery in patients with pelvic malignancies. Radiother Oncol. 2012;102:325-34.

15. DeLuca FR, Ragins H. Construction of an omental envelope as a methe od of excluding the small intestine from the field of postoperative irradiation to the pelvis. Surg Gynecol Obstet. 1985;160:365-6.

16. Zimmerer T, Böcker U, Wenz F, Singer MV. Medical prevention and treatment of acute and chronic radiation induced enteritis--is there any proven therapy? a short review. Z Gastroenterol. 2008;46:441-8.

17. Henson CC, Burden S, Davidson SE, Lal S. Nutritional interventions for reducing gastrointestinal toxicity in adults undergoing radical pelvic radiotherapy. Cochrane Database Syst Rev. 2013;11:CD009896.

18. Stacey R, Green JT. Radiation-induced small bowel disease: latest developments and clinical guidance. Ther Adv Chronic Dis. 2014;5: 15-29.

19. Wedlake LJ, Shaw C, Whelan K, Andreyev HJ. Systematic review: the efficacy of nutritional interventions to counteract acute gastrointestinal toxicity during therapeutic pelvic radiotherapy, Aliment Pharmacol Ther. 2013;37:1046-56.

20. Wedlake LJ, Thomas K, McGough C, Andreyev HJ. Small bowel bacterial overgrowth and lactose intolerance during radical pelvic radiother apy: an observational study. Eur J Cancer. 2008;44:2212-7.

21. Wedlake L, Small bowel bacterial overgrowth and lactose intolerance during radical pelvic radiotherapy: An observational study. Eur J Cancer. 2008;44(15):2212.

22. Gibson PR, Shepherd SJ. Evidence-based dietary management of functional gastrointestinal symptoms: The FODMAP approach. J Gastroenterol Hepatol. 2010;25:252-8.

23. Staudacher HM, Whelan K, Irving PM, Lomer MC. Comparison of symptom response following advice for a diet low in fermentable carbohy drates (FODMAPs) versus standard dietary advice in patients with irritable bowel syndrome. J Hum Nutr Diet. 2011;24:487-95.

24. Khan MA, Nusrat S, Khan MI, Nawras A, Bielefeldt K. Low-FODMAP diet for irritable bowel syndrome: is it ready for prime time? Dig Dis Sci. 2015;60:1169-77.

25. Halmos EP, Christophersen CT, Bird AR, Shepherd SJ, Gibson PR, Muir JG. Diets that differ in their FODMAP content alter the colonic luminat microenvironment. Gut. 2015;64:93-100.

26. Gearry RB, Irving PM, Barrett JS, Nathan DM, Shepherd SJ, Gibson PR. Reduction of dietary poorly absorbed short-chain carbohydrates (FODMAPs) improves abdominal symptoms in patients with inflammatory bowel disease - a pilot study. J Crohns Colitis. 2009;3:8-14.

27. Prince AC, Myers CE, Joyce T, Irving P, Lomer M, Whelan K. Fermentable carbohydrate restriction (low FODMAP diet) in clinical practice im:proves functional gastrointestinal symptoms in patients with inflammatory bowel disease. Inflamm Bowel Dis. 2016;22:1129-36.

28. Fayers PM, Aaronson NK, Bjordal K, Groenvold M, Curran D, Bottomley A; on behalf of the EORTC Quality of Life Group. The EORTC QLQ-C30 Scoring Manual (3rd Edition). Published by: European Organisation for Research and Treatment of Cancer, Brussels 2001.

29. Aaronson NK, Ahmedzai S, Bergman B, et al. The European Organisation for Research and Treatment of Cancer QLQ-C30: A quality-of-life instrument for use in international clinical trials in oncology. J Natl Cancer Inst. 1993;85:365-76.

30. Greimel ER, Kuljanic Vlasic K, Waldenstrom AC, et al. The European Organization for Research and Treatment of Cancer (EORTC) Quality-of-Life Questionnaire Cervical Cancer Module: EORTC QLQ-CX24. Cancer. 2006;14:1812-22.

31. Greimel E, Nordin A, Lanceley A, et al. Psychometric validation of the European Organisation for Research and Treatment of Cancer Quality of Life Questionnaire-Endometrial Cancer Module (EORTC QLQ-EN24). Eur J Cancer. 2011;47;183-90.

32. U.S. Department of Health and Human Services, Common Terminology Criteria for Adverse Events (CTCAE) Version 4.03, June 14, 2010. 